\author{
광섬유-평면도파로 결합기를 이용한 광변색성 \\ 디아릴에텐 유도체의 광유도 굴절률 변화에 관한 연구 \\ 조강민 · 윤정현 \\ 경북대학교 센서공학과 \\ (ㅇ) 702-701 대구광역시 북구 산격동 1370번지 \\ 임선정 - 박수영 \\ 서울대학교 재료공학부 \\ (ㅇ) 151-744 서울특별시 관악구 신림9동 산 56-1번지 \\ 강신원 ${ }^{+}$ \\ 경북대학교 전자전기공학부 \\ (ㅇ) 702-701 대구광역시 북구 산격동 1370번지 \\ (2003년 10월 29일 받음, 2004년 2월 17일 수정본 받음)
}

\begin{abstract}
광섬유와 평면도파로 결합기의 소산장 결합을 이용하여 디아릴에텐 유도체 DM-BTE(1,2-bis[2,5-dimethylthio-phen-3-yl]hexafluorocyclopentene)의 광유도 굴절률 변화(photo-induced refractive index change)에 관하여 그 특성을 평가하였다. DM-BTE가 분산된 평면도파로는 자외선과 가시광선 $(\lambda>450 \mathrm{~nm})$ 의 조사에 의해 광변색 반응이 가역적으로 진행되었으며 굴절률변화에 의한 공명 파장 또한 가역적으로 이동하였다. 광변색 반응이 진행되는 동안 평면도파로의 결정상태(crystal shape)는 일정한 형태를 유지하였으 며, 자외선 조사시간에 대한 소자의 파장웅답은 $0.057 \mathrm{~nm} / \mathrm{sec}$ 이었고 포화시간은 $60 \mathrm{sec}$ 로 나타났으며, 가시광선이 다시 조사될 때의 공명파장의 변화는 $0.028 \mathrm{~nm} / \mathrm{sec}$ 이었고, 복귀시간은 $140 \mathrm{sec}$ 로 측정 되었다.

주제어 : side-polished fiber, photo-functional polymer, diarylethene(DM-BTE), fiber-to-planar waveguide coupler.
\end{abstract}

\section{I. 서 론}

현재 대용량, 초고속의 정보처리 시스템의 개발과 더불어 광메모리, 광스위치, 광변조기 등 빛을 이용한 정보통신소자 부품에 이용될 수 있는 핵심 소재에 대한 필요성이 높아지고 있다. ${ }^{[1]}$ 유기 광변색 물질(photochromic material)은 광조사 (photo-irradiation)에 의해 두 이성질체가 가역적으로 변화하 는 화합물이며 광변색 반웅이 진행되는 동안 흡수스펙트럼 뿐만 아니라 유전상수, 굴절률, 산화-환원 전위 등 물리화학 적 특성이 변화 한다. ${ }^{[2-5]}$ 이러한 유기 광변색 물질 중 디아릴 에텐(diarylethene) 유도체는 기존의 광변색 물질에 비해 열 적 안정성(thermal stability)이 매우 우수하며 피로 저항도 (fatigue resistance)가 높고 광변색 반옹속도(response time)가 빨라 이를 광메모리 및 광스위치용 소재로 응용하기 위한 많 은 연구가 진행되고 있다. [5-6]

본 연구에서 사용된 디아릴에텐 유도체 1,2-bis(2,5-dimethylthiophen-3-yl)hexafluoro-cyclo pentene(DM-BTE)은 용액과 단결정을 포함한 고체상태에서 자외선과 가시광선의 조사에 의해 가역적인 광변색 반응이 진행되는 것으로 보고 되어 있

\footnotetext{
${ }^{\dagger}$ E-mail: swkang@ knu.ac.kr
}

다. ${ }^{[7]}$ 본 연구에서는 측면 연마된 광섬유와 DM-BTE가 분산 된 평면도파로 결합기의 소산장 결합을 이용한 광유도 굴절 률 변화에 관하여 그 특성을 평가하였다.

\section{II. 동작원리}

그림 1 은 평면도파로에 분산된 광변색성 디아릴에텐 유도 체 DM-BTE의 광변색성 화학구조 변화를 나타낸다. DMBTE는 그림 1과 같이 자외선에 노출되면 폐환구조가(closedring form: B state)되면서 붉은색을 나타내고, 가시광선의 조 사(>450 nm)에 의해 개환구조(open-ring form: A state)가 되 면서 초기의 무색으로 되돌아오는 가역적인 광변색 반응을 한다.

그림 2는 DM-BTE의 자외선 조사전과 조사후의 UV-Visible 흡수 스펙트럼을 나타내고 있다. 흡수 스펙트럽에서 알 수 있는 바와 같이 자외선 조사 후 폐환구조의 광 이성질체가 형성됨에 따라 가시광선 영역대에서 흡수 $(\lambda \max =512 \mathrm{~nm})$ 가 일어나 붉은색을 나타내는 것임을 확인할 수 있다.

측면 연마된 광섬유와 평면도파로 결합기를 이용한 센서는 두 가지 방법을 통한 결과 분석이 이루어진다. 첫 번째는 외부 변화에 대한 공명파장의 이동을 통한 분석(wavelength based 
method)이고, 두 번째는 외부변화에 대한 단 파장(laser)의 transmission 변화를 통한 분석(intensity based method)이다. ${ }^{[8]}$ 본 연구에서는 DM-BTE가 분산 된 평면도파로의 광변색 반 응의 진행에 따른 굴절률의 변화를 이용하여 광섬유평면도 파로 결합기에서 일어나는 mode coupling의 이동을 wavelength based method를 통하여 분석하였다.

그림 3은 측면 연마된 광섬유와 평면도파로 결합기의 구조 를 나타낸 것이다. 제작된 평면도파로는 polystyrene(50 wt\%, $\mathrm{n}=1.58)$ 에 DM-BTE가 분산된고분자로 이루어졌다. 측면이 연마된 광섬유는 코어 $(\mathrm{n}=1.448 @ 1.55 \mu \mathrm{m})$ 직경이 $8.2 \mu \mathrm{m}$ 이 고, design wavelength가 $1.31 \mu \mathrm{m}$ 인 단일모드 광섬유로 제작 되었다.

광섬유와 평면도파로의 위상정합으로 인하여 특정파장에 서 광결합이 발생하게 되고, 이 결과로 mode coupling이 나 타난다. $^{[9]}$ 이때 제작된 센서 지지대의 상단부인 DM-BTE가 분산 된 평면도파로는 자외선이 조사되면 폐환구조(closering form)의 형성에 의해 굴절률의 변화가 일어나면서 공진 파장이 이동하게 된다. 그리고 평면도파로에 가시광선을 조 사하게 되면 평면도파로는 가역적으로 개환구조가 되면서

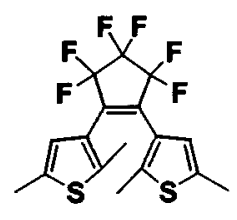

Open-ring form A state (Colorless)
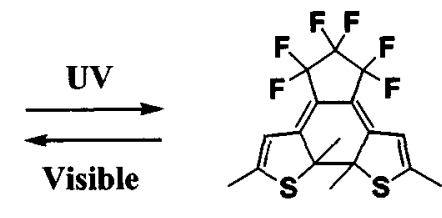

Close-ring form B state (Red)
그림 1. 1, 2-bis(2,5-dimethylthiophen-3-yl)hexafluo rocyclopentene (DM-BTE)의 광변색 반응.

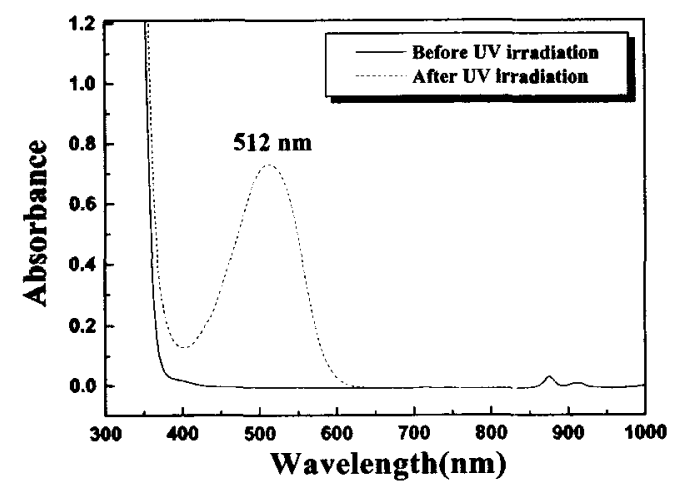

그립 2. DM-BTE의 광변색 반웅 진행에 따른 UV-Vis. 홉수 스펙트 럼의 변화.

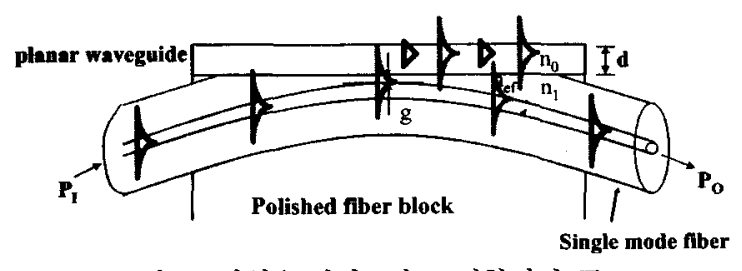

그림 3. 광섬유 명면도파로 결합기의 구조. (open-ring form) 다시 초기의 공진파장의 위치로 돌아오게 된다. 측면 연마된 광섬유와 평면도파로 결합기에서, 측면이 코어 가까이 연마된 단일모드 광섬유 위에 다중모드를 가지 는 평면도파로 층이 형성되면 두 광 경로 사이에 소산장 결 합(evanescent field coupling)이 형성되어 광에너지 교환이 발생하게 된다. ${ }^{[10,11]}$

평면도파로는 여러 모드를 가질 수 있으며 이 중에 광섬유 모드와 위상정합(phase matching)조건을 만족하는 모드가 효 과적인 광 결합을 일으킨다. 다중모드를 가지는 평면도파로 의 $\mathrm{m}$ 번째 모드의 유효굴절률을 찾기 위한 고유치 방정식은 다음과 같다. ${ }^{[12]}$

$$
\frac{2 \pi d_{0}}{\lambda}\left(n_{o}^{2}-n_{e o}^{2}\right)^{1 / 2}=m \pi+\psi_{1}+\phi_{2}
$$

$\mathrm{m}$ : 모드의 차수(정수), $\lambda$ : 광의 파장

$d_{0}$ : PWG 코어충 두께, $n_{0}$ : PWG 코어 굴절률

$n_{e 0}: \mathrm{m}$ 번째 고차모드 유효 굴절률

광섬유-평면도파로 결합기가 광결합을 일으키기 위해서는 광섬유의 유효굴절률 $\left(n_{e f}\right)$ 과 평면도파로의 유효굴절룰 $\left(n_{e o}\right)$ 이 일치해야 한다. 평면도파로의 최고차 모드가 가장 작은 유효굴절률을 가지기 때문에 광섬유의 유효굴절률과 가장 근접하게 되고 식 (1)에 $n_{e o}=n_{e f}$ 을 대입하면 평면도파로 $\mathrm{m}$ 차 모드에서 공진하는 파장 $\left(\lambda_{m}\right)$ 을 아래와 같이 구할 수 있다.

$$
\lambda_{m}=\frac{2 d \pi\left(n_{0}^{2}-n_{e f}^{2}\right)^{1 / 2}}{m \pi+\phi_{1}+\phi_{2}}
$$

광섬유평면도파로 결합기는 센서 응용시 $\mathrm{TE}$ 응답과 $\mathrm{TM}$ 응 답 중 한쪽 편광만을 관측함으로써 자외선량의 변화에 따른 파장응답을 관측할 수 있다.

\section{III. 측정 및 결과}

그림 4는 제작된 소자의 동작특성을 관측하기 위한 장치도 이다.

광섬유 곡률을 유지하면서 클래드 층의 측면을 연마하기 위해서는 광섬유 연마지지대 ${ }^{[13]}$ 를 필요로 한다. 측면연마 방법 은 석영(quartz) ${ }^{[14]}$ 이나 실리콘(V-groove의 MEMS 공정) ${ }^{[15,16]}$ 등의 연마지지대를 이용하여 연마하거나 광섬유자체를 식각

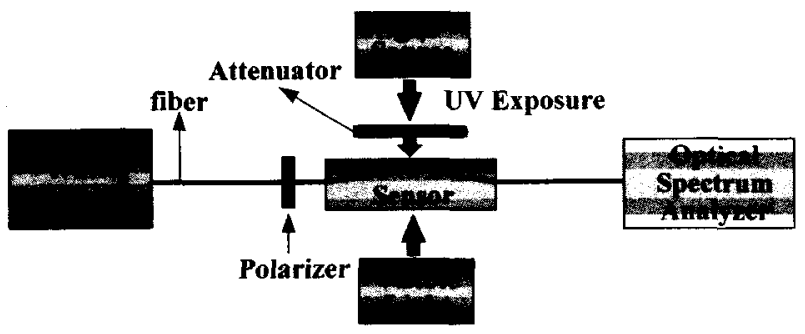

그림 4. 측정 장치도. 
용액을 사용하여 화학적 반응을 통해 식각하는 방법 ${ }^{[17]}$ 등이 있지만, 본 연구에서는 제작이 용이하며, 연마 상태가 양호 한 석영블록의 지지대를 이용하여 측면을 연마하는 방법을 사용하였다. 곡률 반경은 출력되는 광강도의 소실을 고려하 면서 소산파에 의해 일어나는 mode coupling이 가장 효과적 으로 발생하게 하는 $25 \mathrm{~cm}$ 로 곡률 반경을 유지하였다. ${ }^{[18]}$

백색광원(white light source)과 광 스폑트럼 분석기(optical spectrum analyzer)를 이용하여 자외선과 가시광선에 의한 공 진 파장의 변화를 실시간으로 관측하였다. 자외선의 조사를 위해 deep UV lamp를 사용하였으며, 자외선의 광강도는 광 감쇄기를 이용하여 $5 \mathrm{~mW}$ 로 고정하여 조사하였고, 자외선을 조사한 후 자외선을 차단함과 동시에 가시광선 또한 차단하 여 DM-BTE가 붉은 색의 폐환 구조를 계속해서 유지하는지 를 그림 5 와 같이 관측하였다. 이때 가시광선을 조사할 때 lamp와 같은 측정 장비에서 발생하는 열에 의해 평면도파로 가 온도에 의한 영향이 미치지 않는 거리를 유지하면서 조사 하는 것이 중요하다. 열에 의한 공명파장의 이동과 자외선에 의한 공명파장의 이동은 서로 상반되기 때문이다.

그림 5 는 평면도파로에 자외선이 조사되었을 때와 차단되 었을 때의 공명파장의 이동을 조사시간의 증가에 따른 변화 로 나타낸 그래프이다. line 1에서 보면 자외선에 조사되기 전에는 개환 구조(A state)로 존재하게 되며, 일정량의 자외 선이 조사되면 폐환 구조(B state)가 되면서 붉은 색을 띄게

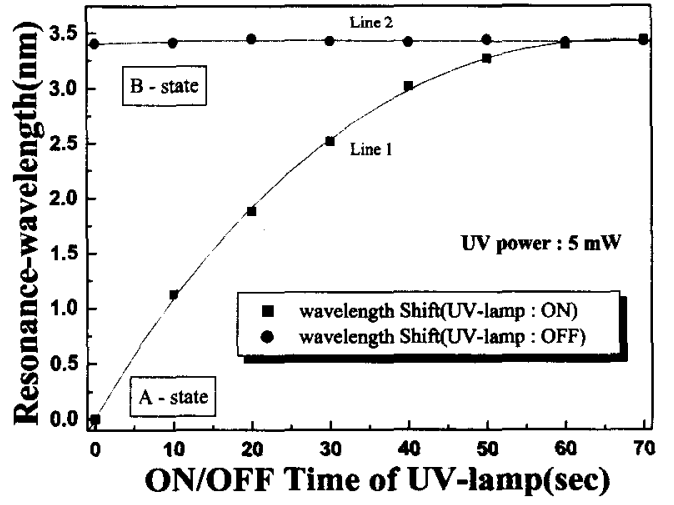

그림 5. 자외선 조사 $\mathrm{ON} / \mathrm{OFF}$ 시간에 따른 투과 스펙트럼.

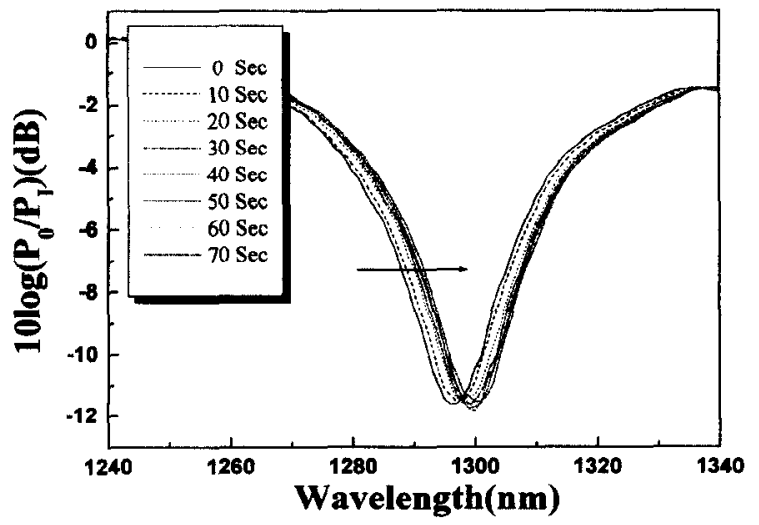

그림 6. 자외선 조사시간의 증가에 따른 투과 스펙트럽.
되고 이와 같은 평면도파로 내의 광변색 분자의 구조적인 변 화에 의해 공명파장은 이동하게 된다. 그리고 가시광선을 완 전히 차단한 상태에서 평면도파로에 조사되는 자외선을 $\mathrm{OFF}$ 시키게 되면 line 2처럼 폐환 구조(B state)가 계속 유지됨을 관찰할 수 있다. 이러한 투과스펙트럼을 통하여 자외선의 광 원을 이용한 공명파장의 동작특성을 임의적으로 이동과 정 지로 조절할 수 있다. 여기에 가시광선을 이용한다면 가역적 으로 공명파장을 처음상태로 복귀시킬 수도 있게 된다.

그림 6은 자외선 조사강도를 $5 \mathrm{~mW}$ 로 고정하고 자외선 조사 시간을 증가시킬 경우에 공명파장의 이동이 오른쪽으로 일 어나게 된다는 것을 나타내고 있으며, 이때 $0.057 \mathrm{~nm} / \mathrm{sec}$ 의 파장응답을 보였다. 공명파장의 이동은 $60 \mathrm{sec}$ 에서부터 포화 되기 시작하였으며, 평면도파로는 붉은색으로 변화됨을 확인 할 수 있었다.

그림 7은 외부 가시광선에서 완전히 밀폐된 dark 상태에서 자외선의 조사를 차단시킬 경우, 자외선에 의해 이동한 공명 파장이 정지된 상태로 지속됨을 나타낸다. 위의 투과스펙트 럽은 자외선에 의해 공명파장의 이동이 포화된 상태에서의 정지를 나타낸다. $50 \mathrm{sec}$ 이상 지속 시에도 여전히 공명파장 이 일정한 상태로 유지됨을 확인할 수 있다.

그림 8은 그림 7에서와 같이 자외선의 조사 후 일정한 상 태를 유지하고 있는 공명파장을 가시광선 lamp를 조사하여 공명파장의 초기상태로 복귀하는 스펙트럼을 나타내고 있다.

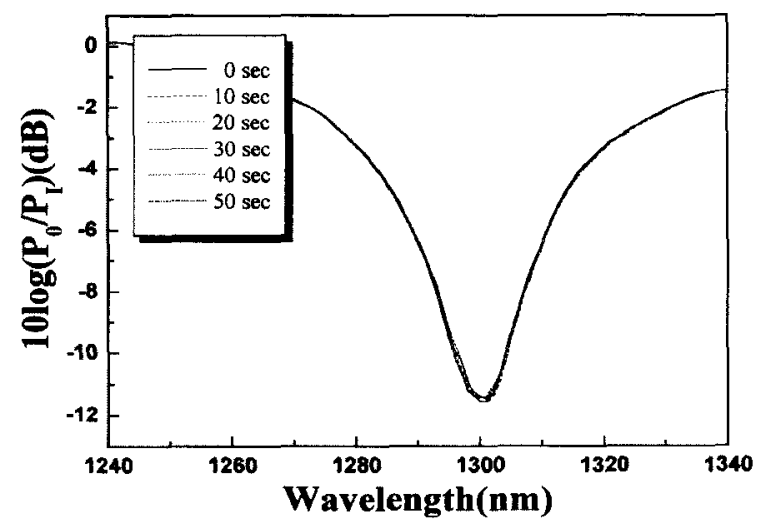

그림 7. 자외선의 차단에 따른 투과스펙트럼.

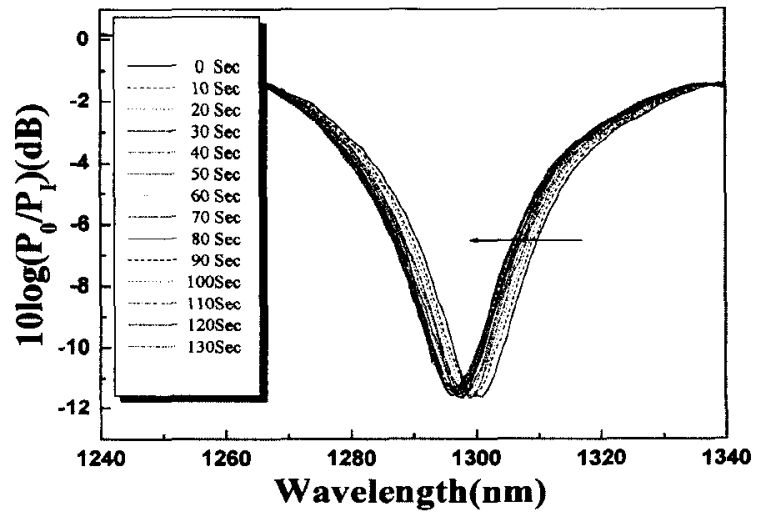

그림 8. 가시광 램프의 조사시간의 중가에 따른 투과스펙트럼. 


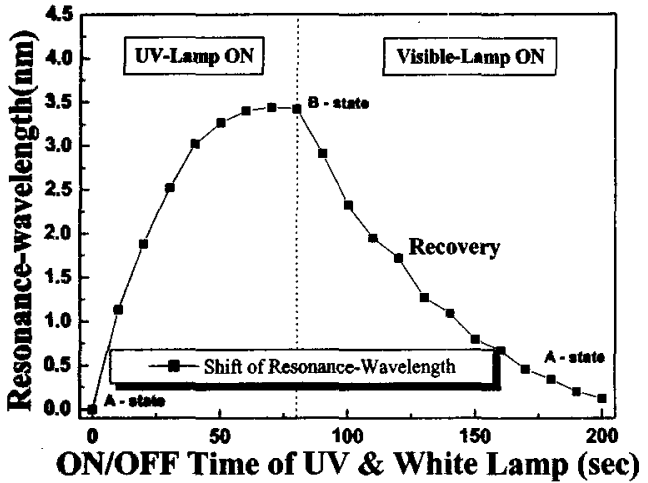

그립 9. 자외선, 가시광의 조사시간 증가에 따른 공명파장 이동의 포화·회복시간.

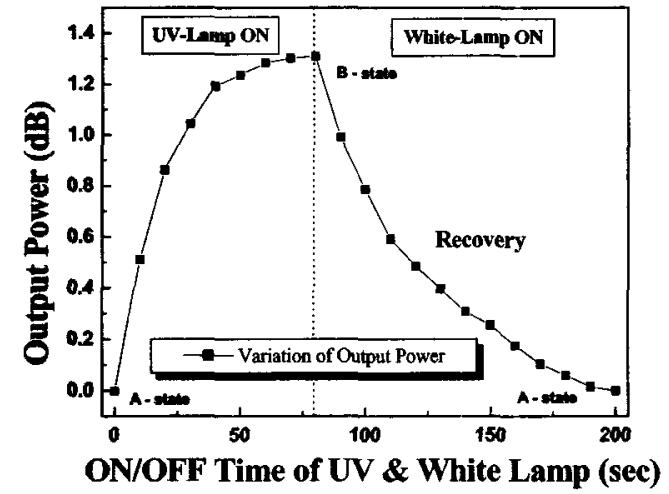

그림 10. 자외선, 가시광의 조사시간 중가에 따른 출력 광강도 변 화의 포화·회복시간 $(\lambda=1310 \mathrm{~nm})$.

가시광선의 조사시간을 증가시킬 경우에 공명파장은 왼쪽으 로 이동하게 되며, 이때 $0.028 \mathrm{~mm} / \mathrm{sec}$ 의 파장응답을 보였다.

그림 9는 자외선과 가시광선의 조사시간 증가에 따른 공명 파장 이동의 포화시간 및 회복시간에 관한 특성을 나타낸다. 또한 그림 10 은 특정 파장에서의 출력 광강도의 변화를 자외 선과 가시광선의 조사시간에 따라 나타내었다. 출력광원은 $1.31 \mathrm{~cm}$ 단파장 광원을 사용하였으며, 일정시간이 경과한 후 에는 출력 광강도의 증가가 포화됨을 알 수 있다. 또한 가시 광선의 조사에 의해 다시 초기상태로 복귀됨을 확인 할 수 있다.

자외선 조사시간이 $60 \mathrm{sec}$ 가 될 때 더 이상의 공명파장의 이동 및 출력 광강도의 변화가 일어나지 않았으며, 이때 평 면도파로는 자외선을 차단함과 동시에 가시광선을 조사한 결과 약 $140 \mathrm{sec}$ 에서 자외선 조사 이전의 초기상태인 투명한 색으로 복귀됨을 확인할 수 있었다.

연속적인 자외선과 가시광선의 조사시간 증가에 따른 공명 파장 이동의 포화시간 및 회복시간을 통하여 DM- BTE의 광 유도 굴절률 변화 웅답특성을 알 수 있었다.

\section{IV. 결 론}

본 연구에서는 측면 연마된 광섬유와 광변색성 디아릴에텐 유도체 DM-BTE(1,2-bis(2,5-di-methylthiophen-3-yl) hexafluorocyclopentene)가 분산된 평면도파로 결합기의 소산장결합 을 이용한 광유도 굴절률 변화를 관측하기 위하여 소자를 제 작하고 그 특성을 평가하였다. 자외선의 조사강도를 고정한 상태에서 조사시간을 점점 증가시켰을 때 자외선에 노출된 평면도파로는 굴절률의 변화가 유도되었고 그에 의한 파장 응답은 $0.057 \mathrm{~nm} / \mathrm{sec}$ 으로 나타났다. 자외선에 대한 포화시간 은 $60 \mathrm{sec}$ 로 나타났으며 감도에 대한 상관계수(correlation coefficient)는 0.92 의 선형적인 결과를 보였다. 또한 가시광 선의 조사에 의한 공명파장의 복귀는 $0.028 \mathrm{~nm} / \mathrm{sec}$ 의 파장응 답을 보였으며, 개환 구조의 초기상태로 복귀하는데 $140 \mathrm{sec}$ 가 소요되었고 이 때의 상관계수는 0.94 의 선형적인 결과를 보였다.

유기 광변색 물질과 소재의 특이성 및 제작이 용이한 광섬 유평면도파로 결합기와의 결합을 통한 이러한 소자는 정밀 도와 우수한 감도, 빠른 응답특성 및 원거리 감지기능 등의 특성을 가지고 있어 광스위치 및 광메모리로 사용 될 수 있 을 것으로 생각된다. 또한 평면도파로를 조절할 때 광통신 파장에서의 동작이 가능하기 때문에 다른 광통신 소자 및 장 비와의 접속이 가능하다는 장점을 가질 뿐만 아니라 새로운 구조와 측정방법의 개선을 이루어 다양한 분야에서 응용될 수 있으리라 기대된다.

\section{참고문헌}

[1] 김세훈, 박수영, "광기능성 유기 - 고분자 소재," 재료마 당, vol. 15, no. 4, pp. 5-9, 2002.

[2] J. C. Crano, R. J. Guglielmetti, Organic Photochromic and Thermochromic Compounds, Plenum Press : New York, 1999.

[3] G. Berkovic, "Spiropyrans and Spirooxazines for Memories and Switches," Chem. Rev., vol. 100, pp. 1741-1753, 2000.

[4] Y. Yokoyama, "Fulgides for Memories and Switches," Chem. Rev., vol. 100, pp. 1717-1739, 2000.

[5] M. Irie, "Diarylethenes for Memories and Switches," Chem. Rev., vol. 100, pp. 1685-1716, 2000.

[6] 김은경, "광변색 폴리머를 이용한 광소자 연구," 광학과 기술 7월호, pp. 43-53, 2000.

[7] S. Kobatake, T. Yamada, K. Uchida, N. Kato, and M. Irie, "Photochromism of 1,2-Bis(2,5-dimethyl-3-thienyl) perfluorocyclopentene in a Single Crystalline Phase," J. Am. Chem. Soc. vol. 121, no. 11, pp. 2380-2386, 1999.

[8] D. Flannery, et al, "pH Sensor using Langmuir- Blodgett Overlays on Polished Optical Fibers," Optics Lett., vol. 22, no. 8, pp. 567-569, 1997.

[9] J. K. Yoon, K. M. Cho, S. W. Kang et al. "Controllable 
In-line UV Sensor using a Side-Polished Fiber Coupler with Photo-Functional Polymer", Photonics technology letter, vol. 15, no. 6, pp. 837-839, 2003.

[10] D. Marcuse, "Investigation of Coupling between a Fiber and an Infinite Slab," Optics Lett., vol. 22, no. 8, pp. 567-5669, 1997.

[11] K. P. Panajotove and Andreev Tz. Andreev, "Distributed Coupling between a Single-Mode Fiber and a Planar Waveguide," J. Opt. Soc. Am. B, vol. 11, no. 5, pp. 826-834, May 1994.

[12] W. Johnstone, G. Thursby, D. Moodie, and K. Mccallion, "Fiber-Optic Refractometer that Utilizes Multimode Waveguide Overlay Devices," Opt. Lett., vol 17, no. 21, pp. 1538-1540, Nov. 1992

[13] A. Andreev, B1. Pantchev, Pantchev, P. Danesh, B. Zafirova, and E. Karakoleva, "a-Si:H Film on Side-Polished Fiber as Optical Polarizer and Narrow-Band Filter," Thin Solid Films, vol. 330, pp. 150-156, 1998.

[14] G. W. Seo, K. M. Cho, S. W. Kang et al. "Side polished fiber optic UV sensor based on evanescent coupling of polymer planar waveguide," Sensor conerence 2002, vol. 13, no. 1, pp. 252-255, 2002.

[15] W. G. Jung, S. W. Kang et al. "High-Sensitivity Temperature Sensor Using a Side-Polished Single-Mode Fiber Covered With the Polymer Planar Waveguide," IEEE Photonics Technology Letters, vol. 13, no. 11, pp. 12091211, 2001.

[16] J. K. Yoon et al. "Side-Polished Fiber Optic Pressure Sensor based on Stress Optical Property of Polymer Planar Wave-Guide," Sensor \& Materials, vol. 14, no. 4, pp. 219-230, 2002.

[17] Tien-jung Chen and Shu-hsia Chen, "Propagation of Lower-order Modes in a Radially Anisotropic Cylindrical Waveguide with Liquid Crystal Cladding," IEEE J. Lightwave Tech., vol. 13, no. 8, pp. 1698-1705, 1995.

[18] Shiao-Min Tseng, Chin-Lin Chen, "Side-Polished Fiber," Appl. Optics, vol. 31, no. 18, pp. 3438-3447, 1992.

\title{
Study on the photo-induced refractive index change of diarylethene derivative using fiber-to-planar waveguide coupler
}

\author{
Kang-Min Cho and Jung-Hyun Yun \\ Department of Sensor Engineering, Kyungpook National University, \\ Daegu 702-701, KOREA \\ Seon Jeong Lim and Soo Young Park \\ School of Materials Science Engineering, Seoul National University, \\ Seoul 151-744, KOREA \\ Shin-Won Kang ${ }^{\dagger}$ \\ School of Electronic and Electrical Engineering, Kyungpook National University, \\ Daegu 702-701, KOREA \\ ${ }^{+}$E-mail: swkang@kmuac.kr
}

(Received October 29, 2003, Received manuscript February 17, 2004)

\begin{abstract}
We have manufactured and characterized the fiber-to-Planar Waveguide Coupler for analysis of the photo-induced refractive index change of DM-BTE (1,2-bis[2,5-dimethylthio-phen-3-yl]-hexafluorocyclopentene). When irradiated with ultraviolet light, the colorless diarylethene(DM-BTE)-crystal turned red while keeping the crystal shape. The red color was bleached by irradiation with visible light $(\lambda>450 \mathrm{~nm})$. The resonant wavelength was shifted and recovered owing to the refractive index variation of the planar waveguide because of its photo-functional properties on exposure to UV and visible light. The wavelength responses of this switch by UV exposure were measured as $0.057 \mathrm{~nm} / \mathrm{sec}$ with saturation time of 60 seconds. and when illuminated by visible light, resonance wavelength variations were measured as $0.028 \mathrm{~nm} / \mathrm{sec}$, with recovery time of 140 seconds.
\end{abstract}

OCIS Codes: $060.2370,130.6010,160.3130,310.6860$. 